\title{
Expression profiles of Toll-like receptors in non-small cell lung cancer and idiopathic pulmonary fibrosis
}

\author{
KATERINA D. SAMARA ${ }^{1,2}$, KATERINA M. ANTONIOU ${ }^{1,2}$, KONSTANTINOS KARAGIANNIS ${ }^{2}$, \\ GEORGIOS MARGARITOPOULOS ${ }^{2}$, ISMINI LASITHIOTAKI ${ }^{2}$, \\ ELENI KOUTALA ${ }^{3}$ and NIKOLAOS M. SIAFAKAS $S^{1,2}$ \\ ${ }^{1}$ Department of Thoracic Medicine, University Hospital of Heraklion, Voutes; \\ ${ }^{2}$ Laboratory of Molecular and Cellular Pulmonary Medicine, Medical School, University of Crete; \\ ${ }^{3}$ Laboratory of Haematology, Medical School, University of Crete, 71110 Heraklion, Crete, Greece
}

Received October 27, 2011; Accepted December 5, 2011

DOI: 10.3892/ijo.2012.1374

\begin{abstract}
Patients with idiopathic pulmonary fibrosis (IPF) have a higher incidence of lung cancer. The role of Toll-like receptors (TLRs), a key component of the innate immunity, in interstitial lung diseases (ILDs) and lung cancer pathogenesis is not clarified. TLR2, TLR3, TLR4, TLR7, TLR8 and TLR9 mRNA expression was quantitatively measured by real-time reverse transcriptase polymerase chain reaction (RT-PCR) in bronchoalveolar lavage fluid (BALF) of 16 IPF patients, 16 non-small cell lung cancer (NSCLC) patients and 9 control subjects. TLR2, TLR3, TLR4 and TLR9 protein expression was assessed on BALF T-lymphocytes using flow cytometry. TLR3 mRNA expression was significantly higher in NSCLC compared to IPF $(\mathrm{p}=0.023)$ and controls $(\mathrm{p}=0.001)$. TLR7 mRNA expression levels were significantly higher in both NSCLC and IPF groups compared to controls $(\mathrm{p}=0.029$, $\mathrm{p}=0.009$ ). TLR9 expression at the mRNA level was significantly higher in both NSCLC and IPF groups compared to controls ( $\mathrm{p}=0.01, \mathrm{p}=0.001)$. Finally, TLR2 mRNA expression was significantly higher in IPF patients compared to controls $(\mathrm{p}=0.042)$. Flow cytometry revealed decreased TLR 3 and TLR9 expression in IPF patients compared to the NSCLC group $(\mathrm{p}=0.02, \mathrm{p}=0.014)$ and decreased TLR9 expression in IPF compared with the controls $(\mathrm{p}=0.04)$. TLR2 protein expression was significantly higher in IPF patients compared to NSCLC $(p=0.04)$. Increased expression of endosomal TLRs in NSCLC patients and elevated expression of TLR2 in pulmonary fibrosis are the main results of this study. These results do not provide support for a common TLR pathway hypothesis between NSCLC and IPF.
\end{abstract}

Correspondence to: Dr Katerina D. Samara, Department of Thoracic Medicine, University Hospital of Heraklion, Panepistimiou Ave., Voutes, 71110 Heraklion, Crete, Greece

E-mail:kat_samara@hotmail.com

Key words: toll-like receptors, carcinogenesis, fibrogenesis, T-lymphocytes, adaptive immunity

\section{Introduction}

Idiopathic pulmonary fibrosis (IPF) is a disease with similarities and links to cancer biology (1). A number of pathogenetic hypotheses are shared by both fatal lung diseases, whose main event is aberrant cell proliferation. Genetic alterations, response to growth and inhibitory signals, resistance to apoptosis, myofibroblast origin and behavior, altered cellular communications and intracellular signaling pathways are all fundamental pathogenic hallmarks of both IPF and cancer (1). Furthermore, both diseases are characterized by lack of effective treatment and poor survival, a combination which underlines the need for further research to gain novel information and perspectives.

Toll-like receptors (TLRs) are members of the interleukin-1 receptor (IL-1R) superfamily, well known for their key role in host defense from infection. They are expressed in a variety of cells, including T-lymphocytes, monocytes, dendritic cells, type II alveolar epithelial cells, airway epithelial, smooth muscle cells, and fibroblasts. TLR1, 2, 4, 5 and 6 are primarily expressed on the cell surface and recognize pathogen-associated molecular patterns (PAMPs) derived from bacteria, fungi and protozoa, whereas TLR3, 7, 8 and 9 are exclusively expressed within endocytic compartments and primarily recognize nucleic acid PAMPs derived from various viruses and bacteria $(2,3)$. TLRs are centrally involved in the initiation of the innate and adaptive immune responses. TLR activation regulates antimicrobial responses through proteolytic processing and secretion of potent factors such as defensins and lysozyme, the stimulation of oxidative agents and the enhanced uptake of microorganisms by phagocytic cells $(4,5)$.

Another aspect of TLR involvement in the lung is tissue repair. TLR activation is known to stimulate angiogenesis in vitro and there is in vivo evidence that TLRs might regulate the angiogenic switch (6-8). Although TLRs are essential for protective immunity against infection, inappropriate TLR responses contribute to acute and chronic inflammation, as well as to systemic autoimmune diseases $(9,10)$. Activation of TLR signaling in the steady state maintains tissue architecture. However, in the presence of deregulated inflammation and/or tissue injury, as occurs in fibrogenesis and tumorigenesis, the TLR-driven tissue response may promote tissue remodeling, 
neoangiogenesis and tumor growth by mechanisms that are still poorly defined $(3,11)$. Growing evidence suggests that functional TLRs are expressed on a wide variety of tumor cells and that TLR signaling promotes tumor growth and immune evasion (12-14). Recently TLR4 and TLR9 were found to be strongly expressed in lung cancer tissue (15) and TLR9 was shown to be overexpressed in pulmonary fibroblasts of patients with IPF, thus indicating a possible role for TLR9 in abnormal tissue remodeling (16). Recent observations support the hypothesis that IPF may not be just an inflammatory disorder but rather a complex process characterized by abnormal pneumocyte apoptosis and profound derangement of alveolar renewal, making it, at least in some aspects, more similar to malignant lung disease (1). Further exploring these pathogenetic pathways we tested the hypothesis that TLR signaling could contribute to lung cancer and IPF initiation and progression in a similar way. However, our results do not provide support for a common pathway but rather reveal distinct TLR activation profiles in the two diseases.

\section{Patients and methods}

Patients. Forty-one consecutive patients were enrolled in the study; sixteen patients with the diagnosis of idiopathic pulmonary fibrosis (IPF), sixteen with non-small cell lung cancer (NSCLC) and nine control subjects. All patients were being treated at the Department of Thoracic Medicine, University Hospital of Heraklion, Crete, Greece. Informed consent was obtained from all patients who participated in this study. The study was approved by the Ethics Committee of the University Hospital of Heraklion, Crete.

$I P F$. The diagnosis was based on internationally accepted clinical and imaging criteria (17). In six cases diagnosis was made by video-assisted thoracoscopic surgery (VATS), where the histologic diagnosis of usual interstitial pneumonia (UIP) was obtained. In the remaining ten cases diagnosis was made on the basis of clinical and high-resolution computed tomography (HRCT) criteria: i) bilateral basal or widespread crackles; ii) restrictive ventilatory defect and/or reduction of $\mathrm{DL}_{\mathrm{CO}}$; iii) computed tomography $(\mathrm{CT})$ findings indicative of IPF i.e., predominantly basal and subpleural microcystic or macrocystic honeycombing, with variably extensive groundglass and reticular abnormalities but no consolidation, nodular abnormalities, or other parenchymal abnormalities (apart from centrilobular emphysema); and iv) no history of environmental exposure to a fibrogenic agent or connective tissue disease. In accordance with the aforementioned criteria any known cause of pulmonary fibrosis, such as a systemic connective tissue disorder, was excluded by both immunologic screening and rheumatological clinical evaluation. All IPF patients were newly diagnosed and had not received treatment.

NSCLC. The diagnosis was based on histopathological criteria from bronchial biopsies and cytology from bronchial washings. The patients included in the study were classified as non-small cell lung cancer (NSCLC), specifically: adenocarcinoma $(6 / 16)$ and squamous cell carcinoma (10/16) according to the criteria of WHO (1997). The patients included in the study were newly diagnosed and had not received any treatment for lung cancer at the time of bronchoscopy.
Control group. The control subjects were patients undergoing bronchoscopy for the investigation of haemoptysis, without any pulmonary comorbidities and with normal bronchoscopic findings and cytology results.

\section{Methods}

BAL fluid processing. BALF was obtained from all patients as previously described (18). Briefly, a flexible bronchoscope was wedged into a subsegmental bronchus of a predetermined region of interest based on radiographical findings. A BAL technique was performed by instilling a total of $240 \mathrm{ml}$ of normal saline in 60-ml aliquots, each retrieved by low suction. The BALF fractions were pooled and split equally into two samples. One sample was sent to the clinical microbiology and cytology laboratory and the other sample was placed on ice and used for research. These samples were filtered through sterile gauze (Thompson, Ontario, Canada) and centrifuged at $400 \mathrm{x} \mathrm{g}$ for $15 \mathrm{~min}$ at $4^{\circ} \mathrm{C}$.

Total cell counts were determined using an improved Neubauer counting chamber, and expressed as the total number of cells per $\mathrm{ml}$ of aspirated fluid. The pellet was washed three times with cold PBS-Dulbecco's and the cells were adjusted to a final concentration of $10^{6}$ cells/ml with RPMI-1640 solution plus $2 \%$ FCS. The slide preparation was performed as previously reported (19).

Flow cytometry analysis. The samples were analyzed on an Epics Elite (Coultronics, Luton, UK) fluorescence-activated flow cytometer. The white cells were tightly gated by volume and complexity on a forward $\left(0^{\circ}\right)$ and side light-scattering $\left(90^{\circ}\right)$ mode and by $\mathrm{CD} 45^{+}$expression (pan leukocyte marker). A minimum of $10^{5}$ cells were analyzed in each case. The appropriate control was used for subtraction of the background. The percentage of one- and two-color positive cells and their mean fluorescence intensity (MFI) were measured. TLR expression was determined in the $\mathrm{CD} 45^{+}, \mathrm{CD}^{+}$population (T-lymphocytes). The following mouse anti-human monoclonal antibodies were used for labelling BALF cells: phycocyanate (Pcy-5)-conjugated anti-CD45 $5^{+}$, phycoerythrin (PE)-conjugated anti-CD3 ${ }^{+}$(Immunotech, Marseille, France). Mouse anti-mouse isotype-matched FITC-, PE- or PCy-5conjugated immunoglobulin were used as control antibodies. Fixation and permeabilization of the samples to prepare for flow cytometry analysis of intracellular TLRs was done with the IntraPrep kit (Immunotech, Beckman Coulter, Marseille, France) using formaldehyde and saponin.

RNA isolation and reverse transcription-polymerase chain reaction: RNA extraction and reverse transcription. Total RNA was extracted from each sample using a power homogenizer and the TRIzol ${ }^{\circledR}$ reagent (Invitrogen, Carlsband, CA, USA) according to the manufacturer's instructions. cDNA was synthesized using the Strascript reverse transcriptase kit (Stratagene, La Jolla, CA, USA) as previously described (20).

Real-time RT-PCR. TLRs mRNA expression was measured using a real-time RT-PCR assay with SYBR-Green I. Primers were designed to span introns. $\beta$-actin was used as the internal control, in order to normalize TLR2, TLR3, TLR4, TLR7, TLR8 and TLR9 (Table I). Specifically, $1 \mu \mathrm{l}$ cDNA from all 
Table I. Primer sequences used for quantitative real-time RT-PCR.

\begin{tabular}{|c|c|c|}
\hline Gene & Primer pair sequence $\left(5^{\prime}-3^{\prime}\right)$ & Annealing temperature $\left({ }^{\circ} \mathrm{C}\right)$ \\
\hline$T L R-2$ & $\begin{array}{l}\text { For: GGGTTGAAGCACTGGACAAT } \\
\text { Rev: TTCTTCCTTGGAGAGGCTGA }\end{array}$ & 55 \\
\hline$T L R-3$ & $\begin{array}{l}\text { For: ACACCATCTATTAAAAGACCCATTAT } \\
\text { Rev: TCCAGATTTTGTTCAATAGCTTGTT }\end{array}$ & 62 \\
\hline$T L R-4$ & $\begin{array}{l}\text { For: GGTCACCTTTTCTTGATTCCA } \\
\text { Rev: TCAGAGGTCCATCAAACATCAC }\end{array}$ & 55 \\
\hline$T L R-7$ & $\begin{array}{l}\text { For: GCTATCAGATTCAAAAACAACAGAA } \\
\text { Rev: CACAAACACCTTTGTAGATCACTTCT }\end{array}$ & 55 \\
\hline$T L R-8$ & $\begin{array}{l}\text { For: GGCTTTCTTTCTGAAGTCAGTAGTCT } \\
\text { Rev: TTTCCGTGTAGTTCCAACATAGATAA }\end{array}$ & 58 \\
\hline$T L R-9$ & $\begin{array}{l}\text { For: CTGAGTGAGAACTTCCTCTACAAATG } \\
\text { Rev: TCTTTTGGTAATTGAAGGACAGGTTA }\end{array}$ & 58 \\
\hline$\beta$-actin & $\begin{array}{l}\text { For: CGGCATCGTCACCAACTG } \\
\text { Rev: GGCACACGCAGCTCATTG }\end{array}$ & 60 \\
\hline
\end{tabular}

Table II. mRNA expression of TLRs in NSCLC, IPF and control subjects.

\begin{tabular}{lcccc}
\hline & NSCLC & IPF & Controls & p-value \\
\hline$T L R 2$ & $8.79 \pm 7.47$ & $9.75 \pm 7.54$ & $1.72 \pm 1.63$ & $\mathrm{p} 1, \mathrm{p} 2: \mathrm{NS} ; \mathrm{p} 3=0.042$ \\
$T L R 3$ & $0.83 \pm 0.64$ & $0.007 \pm 0.005$ & $0.0014 \pm 0.0008$ & $\mathrm{p} 1=0.023 ; \mathrm{p} 2=0.001 ; \mathrm{p} 3: \mathrm{NS}$ \\
$T L R 4$ & $5.26 \pm 3.2$ & $2.34 \pm 1.61$ & $12.37 \pm 12.24$ & $\mathrm{p} 1, \mathrm{p} 2, \mathrm{p} 3: \mathrm{NS}$ \\
$T L R 7$ & $11.79 \pm 7.36$ & $5.06 \pm 4.12$ & $1.5 \pm 1.35$ & $\mathrm{p} 1: \mathrm{NS} ; \mathrm{p} 2=0.029 ; \mathrm{p} 3=0.009$ \\
$T L R 8$ & $5.78 \pm 4.7$ & $11.14 \pm 7.89$ & $8.67 \pm 8.51$ & $\mathrm{p} 1, \mathrm{p} 2, \mathrm{p} 3: \mathrm{NS}$ \\
$T L R 9$ & $17.1 \pm 16.13$ & $3.1 \pm 2.51$ & $0.58 \pm 0.53$ & $\mathrm{p} 1: \mathrm{NS} ; \mathrm{p} 2=0.001 ; \mathrm{p} 3=0.001$ \\
\hline
\end{tabular}

Values are expressed as the mean \pm SEM. $\mathrm{p}<0.05$ is considered statistically significant; NS, non-significant. p1: NSCLC vs. IPF; p2: NSCLC vs. C; p3: IPF vs. C.

patient and control samples was amplified in a PCR reaction containing 2X Brilliant SYBR-Green I QPCR Master mix, $300 \mathrm{nM}$ of each primer and $30 \mu \mathrm{M}$ ROX passive reference dye, in a final volume of $20 \mu \mathrm{l}$. After an initial denaturation at $95^{\circ} \mathrm{C}$ for $10 \mathrm{~min}$, the samples were subjected to 40 cycles of amplification, comprised of denaturation at $95^{\circ} \mathrm{C}$ for $30 \mathrm{sec}$, annealing at appropriate temperature for each primer pair for $30 \mathrm{sec}$ and elongation at $72^{\circ} \mathrm{C}$ for $30 \mathrm{sec}$, followed by a melt curve analysis, in which the temperature was increased from 55 to $95^{\circ} \mathrm{C}$ at a linear rate of $0.2^{\circ} \mathrm{C} / \mathrm{sec}$. Data collection was performed both during annealing and extension, with two measurements at each step, and at all times during melt curve analysis. In each PCR reaction two non-template controls were included. All PCR experiments were conducted on the Mx3000P realtime PCR thermal cycler using the software version 2.00, (Stratagene). To verify the results of the melt curve analysis, PCR products were analyzed by electrophoresis in $2 \%$ agarose gels, stained with ethidium bromide and photographed on a UV light transilluminator.
Primer sequences, annealing temperatures and PCR product length for all the TLRs analyzed, as well as for $\beta$-actin, are shown in Table I. All reactions were run in triplicates, and TLRs transcript levels were calculated and normalized to each specimen's housekeeping gene mRNA ( $\beta$-actin) as well as the appropriate calibrators, using the $\Delta \Delta \mathrm{Ct}$ method for relative quantification (20). Specifically, after amplification, standard curves were constructed from samples used in a series of consecutive dilutions, for both the gene of interest and the internal control ( $\beta$-actin). TLRs and $\beta$-actin amplification efficiencies were the same, reaching $100 \%$. Data from all three patient groups were first normalized against variation in sample quality and quantity. Normalized values to $\beta$-actin, $\Delta \mathrm{Cts}$, were initially calculated using the following equation: $\Delta \mathrm{Ct}_{\text {sample }}=\mathrm{Ct}_{\mathrm{TLRs}}-\mathrm{Ct}_{\beta}$-actin.

Statistical analysis. TLRs mRNA levels and flow cytometry results were first evaluated by the one-sample KolmogorovSmirnov goodness of fit test, in order to determine whether they 

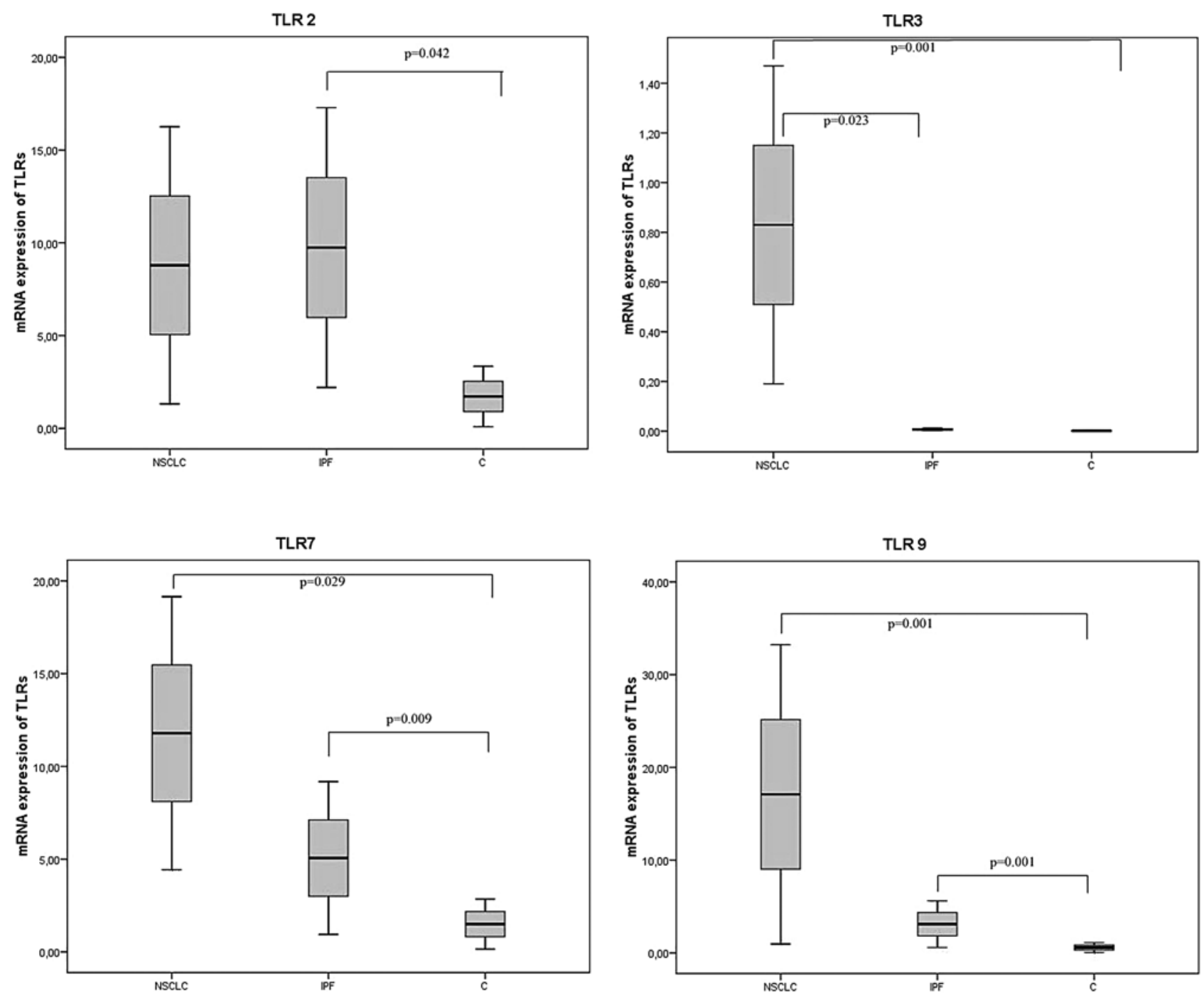

Figure 1. TLR2, 3, 7 and 9 mRNA expression results in BAL fluid cells of patients with NSCLC, IPF and controls (C); values are expressed as the mean \pm SEM.

Table III. Percentage of subjects expressing TLRs mRNA in their BALF cells.

\begin{tabular}{lcccl}
\hline & NSCLC $(\%)$ & IPF $(\%)$ & Controls $(\%)$ & \multicolumn{1}{c}{ p-value } \\
\hline$T L R 2$ & $14 / 16(87.5)$ & $16 / 16(100)$ & $8 / 9(88.9)$ & $\mathrm{p} 1, \mathrm{p} 2, \mathrm{p} 3: \mathrm{NS}$ \\
$T L R 3$ & $7 / 16(43.75)$ & $2 / 16(12.5)$ & $3 / 9(33.3)$ & $\mathrm{p} 1=0.049$ \\
$T L R 4$ & $12 / 16(75)$ & $15 / 16(93.75)$ & $7 / 9(77.7)$ & $\mathrm{p} 1, \mathrm{p} 2, \mathrm{p} 3: \mathrm{NS}$ \\
$T L R 7$ & $12 / 16(75)$ & $15 / 16(93.75)$ & $7 / 9(77.7)$ & $\mathrm{p} 1, \mathrm{p} 2, \mathrm{p} 3: \mathrm{NS}$ \\
$T L R 8$ & $14 / 16(87.5)$ & $16 / 16(100)$ & $9 / 9(100)$ & $\mathrm{p} 1, \mathrm{p} 2, \mathrm{p} 3: \mathrm{NS}$ \\
$T L R 9$ & $11 / 16(68.75)$ & $16 / 16(100)$ & $7 / 9(77.7)$ & $\mathrm{p} 1=0.01 ; \mathrm{p} 2: \mathrm{NS} ; \mathrm{p} 3=0.02$ \\
\hline
\end{tabular}

NS, non-significant. p1: NSCLC vs. IPF; p2: NSCLC vs. Controls; p3: IPF vs. Controls.

follow a normal distribution or not. Values reported are means \pm SEM (standard error of the mean). Friedman one way analysis of variance (ANOVA) was performed and the non-parametric Mann-Whitney U test was used for post-hoc comparisons. Chi-square test was used, as indicated, to examine TLRs 2, 3, 4, 7, 8 and 9 expression status among IPF, NSCLC patient groups and controls. Statistical analysis was carried out using
SPSS 17.0 Chicago IL, USA. Statistical significance was set at the $95 \%$ level $(\mathrm{p}<0.05)$.

\section{Results}

Demographics. Patients in all three groups were of comparable age. The IPF patients had a median age of $67.3 \pm 1.6$ years, twelve 
Table IV. Percentage of TLR-positive BALF T-lymphocytes $\left(\mathrm{CD}^{4} 5^{+}, \mathrm{CD}^{+}\right)$.

\begin{tabular}{lcccc}
\hline & NSCLC $(\%)$ & IPF $(\%)$ & Controls $(\%)$ & p-value \\
\hline$T L R 2$ & $1.94 \pm 0.84$ & $18.4 \pm 13.27$ & $4.22 \pm 1$ & $\mathrm{p} 1=0.04 ; \mathrm{p} 2, \mathrm{p} 3: \mathrm{NS}$ \\
$T L R 3$ & $64 \pm 10.3$ & $32.0 \pm 2.0$ & $53 \pm 18.6$ & $\mathrm{p} 1=0.02 ; \mathrm{p} 2=0.036 ; \mathrm{p} 3: \mathrm{NS}$ \\
$T L R 4$ & $32.9 \pm 5.17$ & $32.45 \pm 5.41$ & $29.3 \pm 8.15$ & $\mathrm{p} 1, \mathrm{p} 2, \mathrm{p} 3: \mathrm{NS}$ \\
$T L R 9$ & $30.9 \pm 2.74$ & $14.85 \pm 3.82$ & $36.8 \pm 8.15$ & $\mathrm{p} 1=0.014 ; \mathrm{p} 2: \mathrm{NS} ; \mathrm{p} 3=0.048$ \\
\hline
\end{tabular}

Values reported are means \pm SEM. $p<0.05$ is considered statistically significant. NS, non-significant. p1: NSCLC vs. IPF; p2: NSCLS vs. Control; p3: IPF vs. Control.

Table V. Mean fluorescence intensity (MFI) of TLR positive BALF T-lymphocytes.

\begin{tabular}{llccr}
\hline & NSCLC & IPF & Controls & p-value \\
\hline$T L R 2$ & $0.88 \pm 0.16$ & $2.48 \pm 0.57$ & $1.45 \pm 0.78$ & $\mathrm{p} 1, \mathrm{p} 2, \mathrm{p} 3: \mathrm{NS}$ \\
$T L R 3$ & $2.29 \pm 0.87$ & $3.32 \pm 0.67$ & $1.84 \pm 0.51$ & $\mathrm{p} 1, \mathrm{p} 2, \mathrm{p} 3: \mathrm{NS}$ \\
$T L R 4$ & $1.59 \pm 0.097$ & $1.49 \pm 0.29$ & $1.53 \pm 0.1643$ & $\mathrm{p} 1, \mathrm{p} 2, \mathrm{p} 3: \mathrm{NS}$ \\
$T L R 9$ & $1.55 \pm 0.18$ & $1.87 \pm 0.22$ & $1.8 \pm 0.3$ & $\mathrm{p} 1, \mathrm{p} 2, \mathrm{p} 3: \mathrm{NS}$ \\
\hline
\end{tabular}

Values reported are means \pm SEM. NS, non-significant. p1: NSCLC vs. IPF; p2: NSCLC vs. Control; p3: IPF vs. Control.

male and four female. The NSCLC patients had a median age of $68 \pm 8.8$ years, all males. The control group (seven males and two females) had a median age of $58.44 \pm 3.49$ years. Fifteen patients in the lung cancer group were current smokers and one patient ex-smoker (smoking history: $66.4 \pm 9.3$ pack years), whereas six patients in the IPF group were non-smokers, nine were ex-smokers and one a current smoker (smoking history: $43.1 \pm 6.7$ pack years). In the control group five subjects were current smokers, one was an ex-smoker (smoking history: $55.6 \pm 11.4$ pack years) and three were non-smokers. As patients in both groups were enrolled in a consecutive, random way, the lung cancer group did not include any women.

TLR mRNA expression. Table II presents the values of mRNA of TLRs studied. TLR2 mRNA expression was significantly higher in IPF patients compared to the control group $(\mathrm{p}=0.042)$, (Fig. 1). TLR3 mRNA expression was significantly higher in the NSCLC group compared to both the IPF group $(p=0.023)$ and controls $(\mathrm{p}=0.001)$. Also, TLR3 mRNA expression $(\%)$ was significantly higher in NSCLC than in IPF $(p=0.049)$, (Table III). TLR4 results were not significantly different between the three groups studied. TLR7 mRNA expression levels were significantly higher in both NSCLC and IPF groups compared to controls $(\mathrm{p}=0.029, \mathrm{p}=0.009)$, (Fig. 1). No statistically significant difference was detected at the mRNA expression levels of TLR8 among all three groups studied. Finally, TLR9 expression at the mRNA level was significantly higher in both NSCLC and IPF groups compared to controls $(\mathrm{p}=0.01, \mathrm{p}=0.001)$.

Flow cytometry results. Table IV shows the percentage of TLR (2, 3, 4 and 9)-positive BALF T-lymphocytes $\left(\mathrm{CD} 45^{+}, \mathrm{CD}^{+}\right)$ as assessed using flow cytometry in all three patients groups studied. The percentage of TLR2 expressing T-lymphocytes was found to be significantly higher in IPF patients compared to NSCLC patients $(\mathrm{p}=0.04)$. Furthermore, our results revealed increased levels of TLR3 expression in NSCLC compared to both IPF $(p=0.02)$ and controls $(p=0.036)$. No significant difference was detected regarding TLR4 expression levels amongst the study groups. Finally, TLR9 expression was decreased in IPF when compared to both NSCLC $(\mathrm{p}=0.014)$ and controls ( $p=0.048)$, (Fig. 2). The mean fluorescence intensity (MFI) of TLR-positive cells between all groups studied did not exhibit any significant differences (Table V).

\section{Discussion}

The main findings of this study are the increased expression of endosomal TLRs 3, 7 and 9 in NSCLC patients compared to both IPF patients and controls and the increased expression of TLR 2 in the pulmonary fibrosis patients when compared to both lung cancer patients and controls. Endosomal TLRs 7 and 9 exhibited also an increased expression in the IPF group compared to controls.

TLRs 3, 7 and 9 localize to cell endosomes and recognize viral and microbial danger signals (2-4). Endosomal TLRs have been strongly implicated in the pathogenesis of autoimmune diseases, like rheumatoid arthritis (RA) and systemic lupus erythematosus (SLE) $(21,22)$ as well as various cancers such as breast cancer, esophageal cancer and recently TLR3 in colorectal cancer $(23,24)$. Our findings, that TLR3, TLR7 and TLR9 mRNA was strongly expressed in BALF from lung cancer patients compared to a weak expression in normal BALF, together with the strong expression of TLR3 protein in BALF T-lymphocytes by flow cytometry, are in agreement with recent evidence in cell lines and tissue of lung cancer patients $(15,25,26)$. However, TLRs in lung cancer have not 

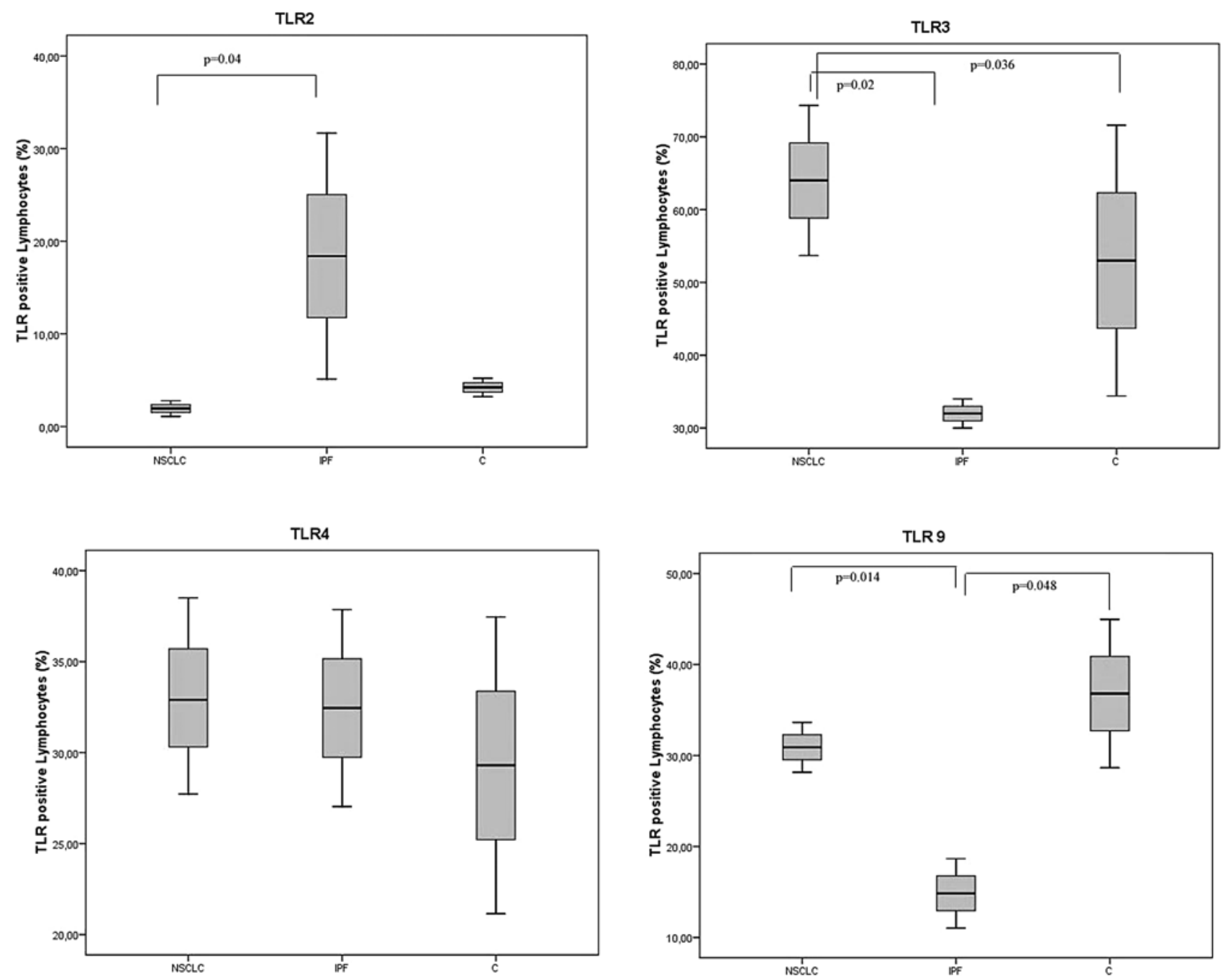

Figure 2. Flow cytometry results: percentage of TLR-positive BALF T-lymphocytes in patients with NSCLC, IPF and controls (C); values are expressed as the mean \pm SEM.

been thoroughly investigated in human studies and, to our knowledge, our study is the first to report that all three endosomal TLRs are concurrently overexpressed. This may suggest that the endosomal TLR pathway activation could play a key role in the development of lung cancer.

Stimulation of endosomal TLRs has been shown to induce a Th1/Th17 type of immune response through activation of $\mathrm{NF}-\kappa \mathrm{B}$, mitogen activated protein kinase and an upregulation of IFN-1 and IFN-inducible genes $(27,28)$. NF- $\kappa$ B plays a critical role in the development of tumors in the context of chronic inflammation. Signaling via TLRs 3,7 and 9 by their ligand, CpG-oligodeoxynucleotide (CpG-ODN), activates $\mathrm{NF}-\kappa \mathrm{B}$ and regulates a variety of pro-inflammatory genes, including interleukin-8 (IL-8), IL-1 and IL-6 which constitute a tumor microenvironment playing a key role in proliferation and survival of genetically altered cells $(29,30)$. The TLR-TRAF6$\mathrm{NF}-\kappa \mathrm{B}$ pathway is known to promote tumor growth in animal models, and our results provide evidence of TLR upregulation in lung cancer BALF that may be associated with activation of $\mathrm{NF}-\kappa \mathrm{B}$ and its involvement in cancer development and progression (31). Apoptosis, a process necessary for tissue remodelling and removal of cells damaged beyond repair, is tightly regulated by many of the same pathways involved in inflammation.
In tumor biology apoptosis is associated with the release of RNA- and DNA-nucleoprotein complexes, which could constitute ligands for TLR activation. Chromatin and DNA immune complexes have been proposed as endogenous ligands for TLR9 and mRNA may act as an endogenous ligand for TLR3 (14). DNA- and RNA-protein complexes released from dying cells could instigate a paracrine activation of endosomal TLRs thus facilitating tumor cell growth and evasion from immune surveillance $(15,16)$. This hypothesis is supported by the findings of our study that showed an overexpression of all three endosomal TLRs in NSCLC patients.

Although TLR signaling seems to be involved in tumor growth and immune system evasion, their involvement in cancer immunotherapy is also of great importance. Various microbial products have been used as adjuvants to enhance antitumor immune responses and they act by stimulating TLR signaling and activation of both innate and adaptive immune responses to enhance tumor immunotherapy (33). A human study provided evidence in a randomized clinical trial setting that a synthetic, TLR9-activating ligand may enhance the clinical activity of chemotherapy in the treatment of NSCLC, exhibiting synergistic anti-tumor activity $(34,35)$. In contrast, Cherfils-Vicini et al concluded that stimulation of human lung 
tumor cell lines with TLR7 or TLR8 agonists led to activated $\mathrm{NF}-\kappa \mathrm{B}$, upregulated expression of the anti-apoptotic protein $\mathrm{Bcl}-2$, increased tumor cell survival and decreased sensitivity to chemotherapy (26). It is evident that TLRs hold a significant role in the events surrounding lung cancer pathogenesis and progression and our results of TLR mRNA and protein overexpression in NSCLC bronchoalveolar lavage cells support this hypothesis. However, the results of trials using TLR agonists as adjuvants in cancer treatment appear contradictory and warrant further investigation of these novel treatment approaches, as the use of TLR ligands in cancer immunotherapy could be a double-edge sword. As our results of elevated expression of endosomal TLRs in NSCLC represent treatment-naïve patients and do not support the use of agonists for treatment, it is important to study TLR expression in patients after chemotherapy to be able to better predict possible benefits.

TLR2, a unique plasma membrane of the TLR family, recognizes lipid and protein ligands and mediates both Th1 and Th2 immune responses. TLR2 has been implicated in the activation of pro-inflammatory cytokines that enhance tumor metastasis (32). Normal TLR2 expression in our cancer group could be associated with the absence of metastases in these newly diagnosed lung cancer patients. However, the IPF group of patients exhibited a significantly elevated expression of TLR2 compared to both controls and lung cancer patients. Razonable et al have identified in human cell lines TLR-2 as a critical receptor molecule for mediating bleomycin-stimulated pulmonary inflammation and fibrosis via activation of the intracellular signaling pathway that results in the translocation of $\mathrm{NF}-\kappa \mathrm{B}$ and the secretion of TNF- $\alpha$ and IL-1 $\beta$ (36). In a series of in vitro experiments that compared the degree of activation between TLR2-expressing and TLR2-deficient human cells, TLR2 activation was identified as one of the initial critical events that trigger the release of pro-inflammatory cytokine and chemokine secretion during bleomycin exposure. This immunosuppressive tissue microenvironment, established by a BLM-induced TLR2 activation, promotes the deposition of collagens and fibrogenesis $(32,36)$. Our experimental results are corroborated by the increased TLR 2 mRNA expression we detected in BALF samples from IPF patients and the increased protein expression of TLR2 positive T-lymphocytes in BALF samples from IPF patients, as compared to healthy controls. Thus, TLR 2 may be an emerging target for the development of therapeutic agents against fibroproliferative lung diseases.

Furthermore, the pulmonary fibrosis patients group exhibited a significantly increased mRNA expression of TLRs 7 and 9, and an increased protein expression of TLR9 $9^{+}$T-lymphocytes in their BALF when compared to controls. TLR3 IPF mRNA expression was similar to the control expression. This increased TLR7 and 9 expression in BALF cells could be associated to infections and their impact on initiation, maintenance and progression of this chronic fibrotic disease. Viral infections are thought to represent co-factors in the pathogenesis of autoimmune and idiopathic lung fibrosis. Epstein-Barr virus (EBV) has been isolated from lung tissue of patients with IPF (37) and cytomegalovirus (CMV) and human herpes virus-7 and -8 have also been detected in $\operatorname{IPF}(38,39)$. It is possible that viral infections via activation of endosomal TLRs -7 and -9 could have a key role in the pathogenesis of IPF as well as in the acute exacerbation of the disease observed after an infection. Meneghin et al (16) have reported an increased TLR9 expression in biopsies from patients with idiopathic interstitial pneumonias (usual interstitial pneumonia, non-specific interstitial pneumonia) when compared with normal lung biopsies and this expression was localized to areas of marked interstitial fibrosis. In a previous study by our group, addressing TLR involvement in fibrotic and granulomatous disorders, an overexpression of TLR-7 mRNA was shown in patients with IPF versus healthy controls, in agreement with these current results and underlining the possible role of TLRs in the pathogenesis of fibrotic disease (40).

Overall, a comparison between NSCLC and IPF in TLR expression reveals few similarities and mostly differences. Both NSCLC and IPF patients showed increased expression of endosomal TLRs 7 and 9 compared to controls, but NSCLC alone showed increased expression of endosomal TLR3 compared to both IPF and controls. Regarding TLR2, IPF patients exhibited higher expression compared to both lung cancer patients and controls. TLR4 and TLR8 expression was similar in both diseases and the control group as well.

Our study has some limitations. It was not a functional study, as we have not investigated if the overexpression of endosomal TLRs in lung cancer cells compared to fibrosis and controls, had any effect in cellular mechanisms, such as apoptosis and angiogenesis (41). BALF contains a variety of cells, so we do not know which cell type showed the TLR findings. Furthermore, the number of patients studied is relatively small and further studies are needed in order to verify these data in a larger number of patients. Another point to be addressed is that we chose to measure TLR expression with flow cytometry in one BALF cellular population, namely $\mathrm{CD} 45^{+} \mathrm{CD} 3^{+} \mathrm{T}$-lymphocytes. As we aimed to assess TLR signaling in two diseases and compare between them, the T-lymphocyte population emerged as a fitting candidate since they are present in BALF from both diseases, they play a pivotal role in immune surveillance mechanisms (42). In flow cytometry, although MFI, an index of TLR expression per cell was not elevated, the percentage of $\mathrm{TLR}^{+}$lymphocytes was increased. Taken together, these results suggest increased expression of TLRs in the T-lymphocyte subpopulation.

In conclusion, we have shown that NSCLC patients have increased expression of endosomal TLRs compared to both IPF patients and controls. IPF patients exhibit increased expression of TLRs 7 and 9 compared to controls and higher expression of TLR2 compared to both lung cancer patients and controls. These results do not provide support for a common TLR pathway hypothesis, but rather reveal distinct TLR activation profiles between NSCLC and IPF.

\section{References}

1. Vancheri C, Failla M, Crimi N and Raghu G: Idiopathic pulmonary fibrosis: a disease with similarities and links to cancer biology. Eur Respir J 35: 496-504, 2010.

2. Kawai T and Akira S: The role of pattern-recognition receptors in innate immunity: update on Toll-like receptors. Nat Immunol 11: 373-384, 2010.

3. Rakoff-Nahoum S and Medzhitov R: Toll-like receptors and cancer. Nat Rev Cancer 9: 57-63, 2009.

4. Blander JM and Medzhitov R: Regulation of phagosome maturation by signals from toll-like receptors. Science 304: 1014-1018, 2004.

5. Schnare M, Barton GM, Holt AC, Takeda K, Akira S and Medzhitov R: Toll-like receptors control activation of adaptive immune responses. Nat Immunol 2: 947-950, 2001. 
6. Jiang D, Liang J, Fan J, et al: Regulation of lung injury and repair by Toll-like receptors and hyaluronan. Nat Med 11: 1173-1179, 2005.

7. Li M, Carpio DF, Zheng Y, et al: An essential role of the NF- $\kappa \mathrm{B} /$ Toll-like receptor pathway in induction of inflammatory and tissue-repair gene expression by necrotic cells. J Immunol 166: 7128-7135, 2001.

8. Macedo L, Pinhal-Enfield G, Alshits V, Elson G, Cronstein BN and Leibovich SJ: Wound healing is impaired in MyD88-deficient mice: a role for MyD88 in the regulation of wound healing by adenosine A2A receptors. Am J Pathol 171: 1774-1788, 2007.

9. Duncan SR: What is autoimmunity and why it is likely to be important in chronic lung disease? Am J Respir Crit Care Med 181: 4-5, 2010.

10. Salaun B, Romero P and Lebecque S: Toll-like receptors two-edged sword: when immunity meets apoptosis. Eur J Immuno 37: 3311-3318, 2007.

11. Shchors K, Shchors E, Rostker F, Lawlor ER, Brown-Swigart L and Evan GI: The Myc-dependent angiogenic switch in tumours is mediated by interleukin 1beta. Genes Dev 20: 2527-2538, 2006.

12. Smyth MJ, Dunn GP and Schreiber RD: Cancer immunosurveillance and immunoediting: the roles of immunity in suppressing tumor development and shaping tumor immunogenicity. Adv Immunol 90: 1-50, 2006.

13. Huang B, Zhao J, Li H, et al: Toll-like receptors on tumor cells facilitate evasion of immune surveillance. Cancer Res 65 5009-5014, 2005.

14. Huang B, Zhao J, Unkeless JC, Feng ZH and Xiong H: TLR signaling by tumor and immune cells: a double-edged sword. Oncogene 27: 218-224, 2008

15. Zhang YB, He FL, Fang M, et al: Increased expression of Toll-like receptors 4 and 9 in human lung cancer. Mol Biol Rep 36: 1475-1481, 2009.

16. Meneghin A, Choi ES, Evanoff HL, et al: TLR9 is expressed in idiopathic interstitial pneumonia and its activation promotes in vitro myofibroblast differentiation. Histochem Cell Biol 130 979-992, 2008.

17. American Thoracic Society/European Respiratory Society International. Multidisciplinary Consensus Classification of the Idiopathic Interstitial Pneumonias. Am J Respir Crit Care Med 165: 277-304, 2002.

18. Antoniou KM, Tzouvelekis A, Alexandrakis MG, et al: Different angiogenic activity in pulmonary sarcoidosis and idiopathic pulmonary fibrosis. Chest 130: 982-988, 2006

19. Haslam PL and Baughman RP: Report of ERS Task Force: guidelines for measurement of acellular components and standardization of BAL. Eur Respir J 14: 245-248, 1999.

20. Antoniou KM, Soufla G, Lymbouridou R, et al: Expression analysis of angiogenic growth factors and biological axis CXCL12/CXCR4 axis in idiopathic pulmonary fibrosis. Connect Tissue Res 51: 71-80, 2010.

21. Papadimitraki ED, Choulaki C, Koutala E, et al: Expansion of toll-like receptor 9-expressing B cells in active systemic lupus erythematosus: implications for the induction and maintenance of the autoimmune process. Arthritis Rheum 54: 3601-3611, 2006.

22. Roelofs MF, Joosten LA, Abdollahi-Roodsaz S, et al: The expression of toll-like receptors 3 and 7 in rheumatoid arthritis synovium is increased and costimulation of toll-like receptors 3 , 4 , and $7 / 8$ results in synergistic cytokine production by dendritic cells. Arthritis Rheum 52: 2313-2322, 2005.

23. Lim DM, Narasimhan S, Michaylira CZ and Wang ML: TLR-3 mediated NF- $\kappa$ B signaling in human esophageal epithelial cells. Am J Physiol Gastrointest Liver Physiol 297: G1172G1180, 2009.
24. Castro FA, Forsti A, Buch S, et al: TLR-3 polymorphism is an independent prognostic marker for stage II colorectal cancer. Eur J Cancer 47: 1203-1210, 2011.

25. Droemann D, Albrecht D, Gerdes J, et al: Human lung cancer cells express functionally active Toll-like receptor 9 . Respir Res 6: 1, 2005.

26. Cherfils-Vicini J, Platonova S, Gillard M, et al: Triggering of TLR7 and TLR8 expressed by human lung cancer cells induces cell survival and chemoresistance. J Clin Invest 120: 1285-1297, 2010.

27. Trivedi S and Greidinger EL: Endosomal Toll-like receptors in autoimmunity: mechanisms for clinical diversity. Therapy 6 : 433-442, 2009

28. Beutler B, Jiang Z, Georgel P, et al: Genetic analysis of host resistance: Toll-like receptor signaling and immunity at large. Annu Rev Immunol 24: 353-389, 2006.

29. Medzhitov R: Toll-like receptors and innate immunity. Nat Rev Immunol 1: 135-145, 2001.

30. Alexopoulou L, Holt AC, Medzhitov R and Flavell RA: Recognition of double-stranded RNA and activation of NF- $\mathrm{KB}$ by Toll-like receptor 3. Nature 413: 732-738, 2001.

31. Inoue J, Gohda J, Akiyama T and Semba K: NF-kappa B activation in development and progression of cancer. Cancer Sci 98: 268-274, 2007.

32. Yang HZ, Cui B, Liu HZ, et al: Targeting TLR 2 attenuates pulmonary inflammation and fibrosis by reversion of suppressive immune microenvironment. J Immunol 182: 692-702, 2009.

33. Chen K, Huang J, Gong W, Iribarren P, Dunlop NM and Wang JM: Toll-like receptors in inflammation, infection and cancer. Int Immunopharmacol 7: 1271-1285, 2007.

34. Krieg AM: Development of TLR9 agonist for cancer therapy. J Clin Invest 117: 1184-1194, 2007.

35. Manegold C, Gravenor D, Woytowitz D, et al: Randomized phase II trial of a toll-like receptor 9 agonist oligodeoxynucleotide, PF-3512676, in combination with first-line taxane plus platinum chemotherapy for advanced-stage non-small-cell lung cancer. J Clin Oncol 26: 3979-3986, 2008.

36. Razonable RR, Henault M and Paya CV: Stimulation of toll-like receptor 2 with bleomycin results in cellular activation and secretion of pro-inflammatory cytokines and chemokines. Toxicol Appl Pharmacol 210: 181-189, 2006.

37. Tsukamoto K, Hayakawa H, Sato A, Chida K, Nakamura H and Miura K: Involvement of Epstein-Barr virus latent membrane protein 1 in disease progression in patients with idiopathic pulmonary fibrosis. Thorax 55: 958-961, 2000.

38. Yonemaru M, Kasuga I, Kusumoto H, et al: Elevation of antibodies to cytomegalovirus and other herpes viruses in pulmonary fibrosis. Eur Respir J 10: 2040-2045, 1997.

39. Tang YW, Johnson JE, Browning PJ, et al: Herpesvirus DNA is consistently detected in lungs of patients with idiopathic pulmonary fibrosis. J Clin Microbiol 41: 2633-2640, 2003.

40. Margaritopoulos GA, Antoniou KM, Karagiannis K, et al: Investigation of Toll-like receptors in the pathogenesis of fibrotic and granulomatous disorders: a bronchoalveolar lavage study. Fibrogenesis Tissue Repair 3: 20, 2010.

41. Sorrentino R, Morello S, Grazia Giordano M, Arra C, Maiolino P, Adcock IM and Pinto A: CpG-ODN increases the release of VEGF in a mouse model of lung carcinoma. Int J Cancer 128: 2815-2822, 2011

42. Kabelitz D: Expression and function of Toll-like receptors in T lymphocytes. Curr Opin Immunol 19: 39-45, 2007. 